\title{
A Rare Case of Severe Acute Pancreatitis Complicated with Pancreatic Pseudocysts, Obstructive Jaundice and Intraperitoneal Hemorrhage
}

\author{
Naoyuki Fujita, Keiko Matsumoto, Nobuyuki Shiga, Akiko NonaKa, Yuji Koya, \\ Hidemi Ogawa, Terutaka Tsuda, Masato Tomita, Takanori Fukami, Masakyo Asahara, \\ Yoshikazu Kinoshita* and Makoto HATANI
}

\begin{abstract}
A 58-year-old man visited our hospital because of back pain. Blood examinations revealed the presence of acute inflammation and an increase of pancreatic enzymes. Abdominal computed tomography indicated pseudocysts in the pancreas. The patient was diagnosed as having acute pancreatitis with pseudocysts formation. During the course of the disease, a newly formed pseudocyst in the pancreatic head compressed the common bile duct, leading to the obstructive jaundice. In addition, the rupture of a pseudocyst in the pancreatic tail caused intraperitoneal hemorrhage. This is an interesting case of acute pancreatitis with pseudocysts in which two rare complications developed.
\end{abstract}

(Internal Medicine 35: 785-790, 1996)

Key words: intracystic hemorrhage, biliary obstruction

\section{Introduction}

Pancreatic pseudocysts generally develop in the course of pancreatitis or after traumatic episodes. Life-threatening complications may occur in some of these cases. We encountered a rare case with acute pancreatitis which was complicated by pseudocyst formation resulting in obstructive jaundice and intraperitoneal hemorrhage from a ruptured pseudocyst.

\section{Case Report}

A 58-year-old man with epigastralgia and back pain visited our hospital. There was no significant family history or past history. The patient had been drinking excessive amounts of alcohol for the previous two months, however he had no previous history of alcohol abuse. On August 16, 1994, he felt epigastralgia and radiating pain in the back. Since those symptoms persisted, the patient was admitted to our hospital. Laboratory findings on admission disclosed increases in all pancreatic enzymes and C-reactive protein. Computed tomographic study on admission (Fig. 1A-D) showed the dilatation of main pancreatic duct and the edema in the tissue surrounding the pancreas. In addition, two thin-walled cystic lesions were found; one, $11 \times 7 \mathrm{~cm}$ in size, in the pancreatic body, and the other one, $4 \times 5 \mathrm{~cm}$ in size, in the pancreatic tail. From these findings, the patient was diagnosed as having mild acute pancreatitis with pseudocyst formation under the 1990 revised criteria for grading severity of acute pancreatitis from the Research Committee for Intractable Diseases of the Pancreas, Japanese Ministry of Health and Welfare. Treatment was started immediately with antibiotics, gabexate mesilate and total parenteral nutrition. In spite of the intensive medical treatment, abdominal pain with muscular defense and hypovolemic shock developed on the 18th hospital day. Findings of the arterial blood gas analysis showed a base excess of $-10.4 \mathrm{mEq} / l(\leqq-3$ $\mathrm{mEq} / l)$ and examination of the blood indicated a red blood cell count of $256 \times 10^{4} / \mu \mathrm{l}$, hemoglobin of $8.8 \mathrm{~g} / \mathrm{dl}$, hematocrit of $26.7 \%$ ( $\leqq 30 \%$, post infusion) and fasting blood glucose of 608 $\mathrm{mg} / \mathrm{dl}(\geqq 200 \mathrm{mg} / \mathrm{dl})$ (Table 1). Computed tomographic study (Fig. 2A, B) revealed an increased density in the content of the cyst in the pancreatic tail and intraperitoneal fluid collection around the spleen, suggesting intracystic hemorrhage in the pancreatic tail and a resultant rupture of the cyst. From these findings, the patient was diagnosed as having severe acute

From the Department of Internal Medicine, Rokko Hospital, Kobe and *the Division of Gerontology, Department of Internal Medicine, Kobe University School of Medicine, Kobe

Received for publication February 26, 1996; Accepted for publication July 10, 1996

Reprint requests should be addressed to Dr. Naoyuki Fujita, the Department of Internal Medicine, Rokko Hospital, 5-1 Tsuchiyama-cho, Nada-ku, Kobe 657 




Figure 1. Computed tomographic study on admission. Two thin-walled cystic lesions are noted; one in the pancreatic tail (A), and the other in the pancreatic body (B-D).

Table 1. Laboratory Data on the 18th Hospital Day

\begin{tabular}{lrlr}
\hline Peripheral blood & & Blood urea nitrogen & $11.8 \mathrm{mg} / \mathrm{dl}$ \\
White blood cell & $16,570 / \mu \mathrm{l}$ & Creatinine & $1.3 \mathrm{mg} / \mathrm{dl}$ \\
Red blood cell & $256 \times 10^{4} / \mu \mathrm{l}$ & Fasting blood glucose & $608 \mathrm{mg} / \mathrm{dl}$ \\
Hemoglobin & $8.8 \mathrm{~g} / \mathrm{dl}$ & $\mathrm{Ca}$ & $8.3 \mathrm{mg} / \mathrm{dl}$ \\
Hematocrit & $26.7 \%$ & Amylase & $852 \mathrm{IU} / l$ \\
Platelet & $15.8 \times 10^{4} / \mu \mathrm{l}$ & Lipase & $235 \mathrm{U} / l$ \\
Biochemistry & & Trypsin & $3,000 \mathrm{ng} / \mathrm{ml}$ \\
Total protein & $5.5 \mathrm{~g} / \mathrm{dl}$ & Elastase I & $1,995 \mathrm{ng} / \mathrm{dl}$ \\
Albumin & $2.9 \mathrm{~g} / \mathrm{dl}$ & PSTI & $130.1 \mathrm{ng} / \mathrm{ml}$ \\
Total bilirubin & $1.0 \mathrm{mg} / \mathrm{dl}$ & Serologic & \\
Aspartate aminotransferase & $41 \mathrm{IU} / l$ & C-reactive protein & $4.9 \mathrm{mg} / \mathrm{dl}$ \\
Alanine aminotransferase & $46 \mathrm{IU} / l$ & Urine amylase & $9,100 \mathrm{IU} / l$ \\
Lactate dehydrogenase & $420 \mathrm{IU} / l$ & Blood gas analysis & \\
Alkaline phosphatase & $243 \mathrm{IU} / l$ & pH & 7.231 \\
Leucine aminopeptidase & $52 \mathrm{IU} / l$ & PaO & $79.5 \mathrm{mmHg}$ \\
$\gamma$-glutamyl transpeptidase & $51 \mathrm{IU} / l$ & PaCO & $38.8 \mathrm{mmHg}$ \\
& & Base Excess & $-10.4 \mathrm{mEq} / l$ \\
\hline
\end{tabular}




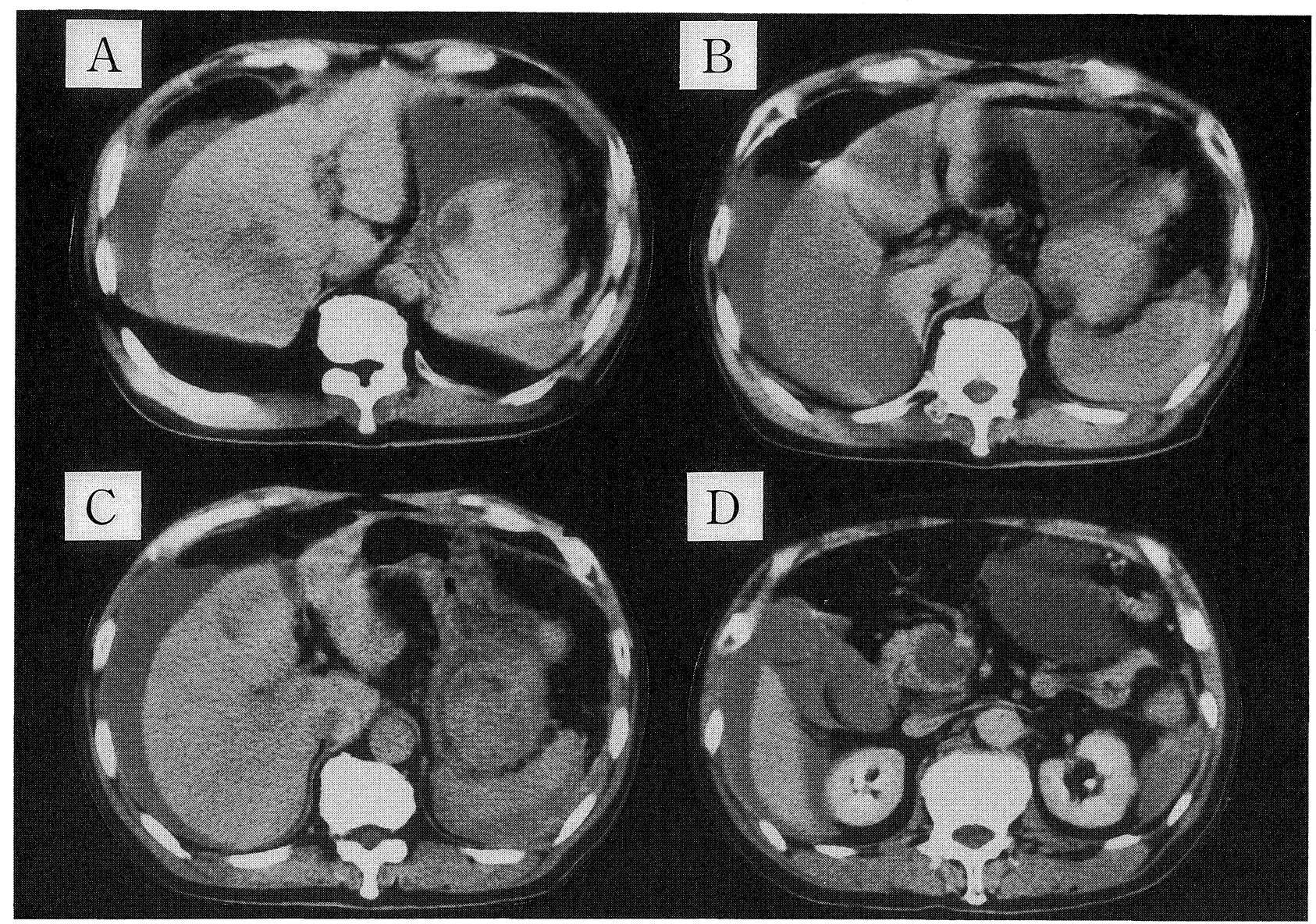

Figure 2. Computed tomographic study on the 18th hospital day (A, B), and computed tomographic study with contrast enhancement on the 19th hospital day $(C, D)$.

pancreatitis under the revised criteria for grading the severity of acute pancreatitis. Computed tomographic study with contrast enhancement on the following day (Fig. 2C, D) indicated the hemostasis of the intraperitoneal hemorrhage and newly formed cyst in the pancreatic head. The dosage of gabexate mesilate administration was increased to $1,000 \mathrm{mg} / \mathrm{day}$. In addition, continuous infusion of ulinastatin 200,000 units/day and citicoline $1 \mathrm{~g} /$ day was started. In spite of these treatments, the direct serum bilirubin concentration began to increase and reached $6.7 \mathrm{mg} / \mathrm{dl}$ on the 30th hospital day. Abdominal ultrasonography showed dilatation of the intrahepatic bile ducts and the proximal part of the common bile duct. Percutaneous transhepatic cholangio drainage and cholangiography were performed (Fig. 3). While the proximal half of the common bile duct was dilated, the intrapancreatic portion of the common bile duct was narrowed by the extramural compression.

On the 55th hospital day, the repeated percutaneous transhepatic cholangiography (Fig. 4) showed the complete obstruction of the common bile duct. Computed tomography taken on that day (Fig. 5A, B) revealed not only the enlargement of the cyst in the pancreas head but also swelling of the pancreas around the cyst, with resulting obstruction of the common bile duct. Consequently, surgical treatment was performed on the 75 th hospital day for the obstructive jaundice. The common bile duct was compressed and obstructed by the cyst in the pancreatic head. Another cyst $4 \times 5 \mathrm{~cm}$ in size was found in the tail of pancreas. The content of the cyst in the tail was a brown colored fluid, indicating old intracystic hemorrhage. In addition, approximately $400 \mathrm{ml}$ of pale blood-colored ascites was observed in the abdominal cavity. Choledocho-ileostomy and gastropancreatic tail cyst anastomosis were performed.

After the surgery, jaundice and pancreatitis temporarily subsided. However, the levels of pancreatic enzymes increased, with the aggravation of pancreatitis. The patient developed disseminated intravascular coagulation, and eventually died on the 126th hospital day.

\section{Discussion}

We report a case of acute pancreatitis with pancreatic pseudocysts, one of which compressed the common bile duct, leading to obstructive jaundice and in the other hemorrhage occurred. Pancreatic pseudocysts typically occur following acute pancreatitis and 2-20 cases are found in 100,000 hospital 


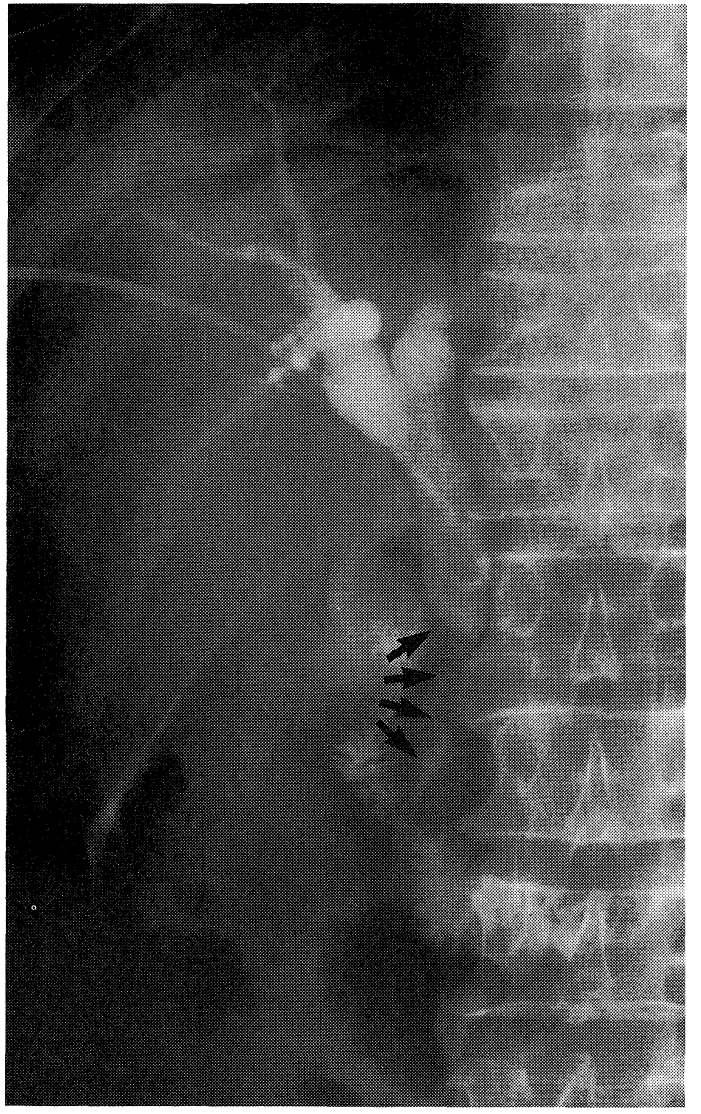

Figure 3. Percutaneous transhepatic cholangiography on the 30th hospital day showed the narrowing of the common bile duct extramural compression (arrows) and leakage of contrast medium into the duodenum.



admissions (1). The major complications of pancreatic pseudocysts are rupture, hemorrhage, and abscess formation. Although a pancreatic pseudocyst, when present in the head of the pancreas, may compress the common bile duct and cause obstructive jaundice, the reports of such cases with this complication are extremely rare (2-9). Pancreatitis is frequently complicated by biliary stenosis and obstructive jaundice as a consequence of fibrotic stricture of the intrapancreatic portion of the common bile duct. Therefore, to confirm that the biliary obstruction is due to the direct compression by pancreatic pseudocysts, four criteria have been proposed (10); I) presence of biliary obstruction, II) surgical demonstration of the compressed common bile duct by a pseudocyst, III) relief of biliary obstruction by drainage of the pseudocyst, and IV) complete

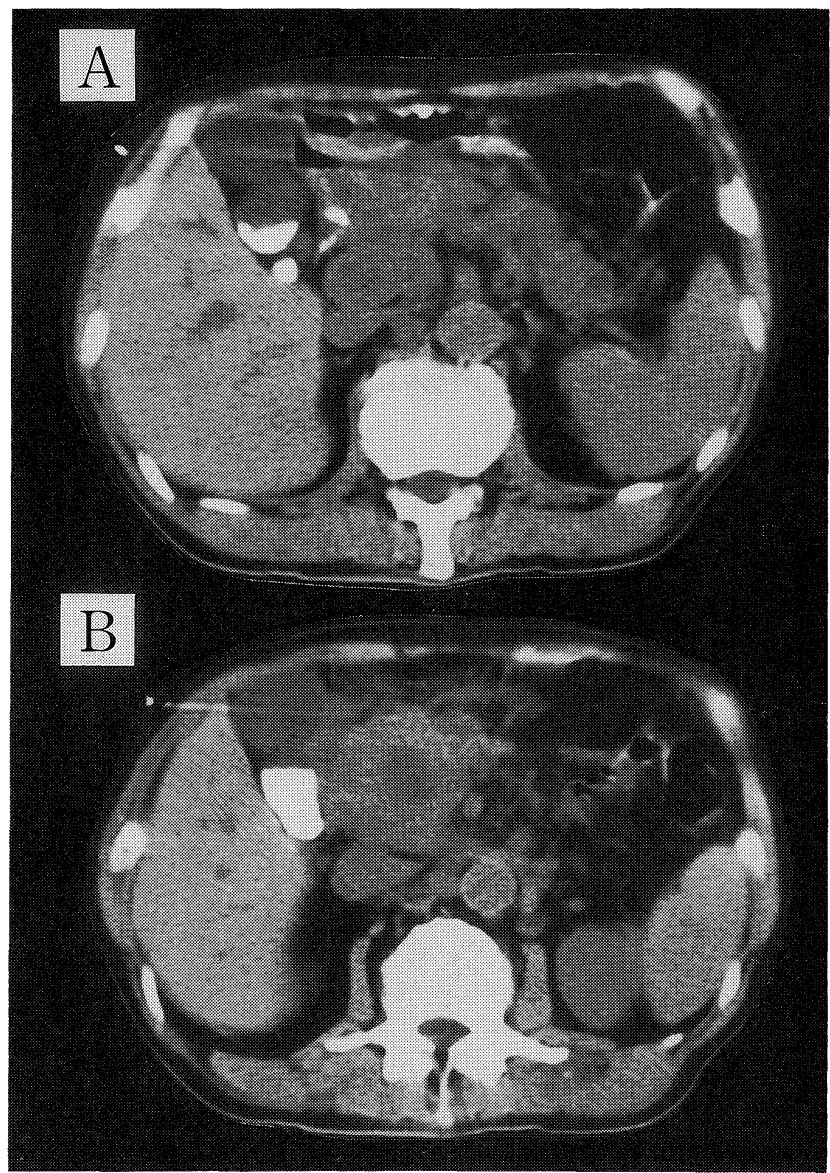

Figure 5. Computed tomography on the 55th hospital day revealed increased size of the cyst and swelling of the pancreas around the cyst $(A, B)$.

Figure 4. Percutaneous transhepatic cholangiography on the 55th hospital day. The common bile duct was completely obstructed at its middle portion and the contrast medium injected into the common bile duct did not leak into the duodenum. 
Acute Pancreatitis with Severe Complications

Table 2. Cases of Pancreatic Pseudocyst Complicated with Intraperitoneal Hemorrhage in Japan

\begin{tabular}{|c|c|c|c|c|c|c|}
\hline No. & Year & Age/sex & Chief complaint & Therapy & Prognosis & Reference \\
\hline 1 & 1983 & $31 / \mathrm{M}$ & up. abd. pain & Operation & Alive & Ishizaki et al (21) \\
\hline 2 & 1984 & $62 / \mathrm{M}$ & low. abd. pain & Conservative & Dead & Harigane et al (22) \\
\hline 3 & 1986 & $34 / \mathrm{M}$ & up. abd. pain & Conservative & Alive & Yamamoto et al (23) \\
\hline 4 & 1987 & $51 / \mathrm{M}$ & up. abd. pain, fever & Hemostasis & Alive & Miyake et al (24) \\
\hline 5 & 1988 & $58 / \mathrm{F}$ & $\begin{array}{l}\text { abd. pain, abd. } \\
\text { distension }\end{array}$ & $\begin{array}{l}\text { Hemostasis of } \\
\text { pseudoaneurysm }\end{array}$ & Alive & Kobayashi et al (25) \\
\hline 6 & 1989 & $69 / \mathrm{M}$ & epigastralgia & Drainage & Alive & Matsui et al (26) \\
\hline 7 & 1989 & $30 / \mathrm{M}$ & lt. hypochondralgia & $\begin{array}{l}\text { Distal pancreatectomy } \\
\text { and splenectomy }\end{array}$ & Alive & Hayashi et al (27) \\
\hline 8 & 1991 & $43 / \mathrm{F}$ & $\begin{array}{l}\text { epigastralgia, } \\
\text { back pain }\end{array}$ & Conservative & Dead & Sekibe et al (28) \\
\hline 9 & 1992 & $50 / \mathrm{M}$ & up. abd. pain & $\begin{array}{l}\text { Distal pancreatectomy } \\
\text { and splenectomy }\end{array}$ & Alive & Fujii et al (29) \\
\hline 10 & 1993 & $51 / \mathrm{M}$ & hematoemesis & Conservative & Dead & Ishitodani et al (30) \\
\hline 11 & 1994 & $47 / \mathrm{M}$ & abd. pain & Conservative & Dead & Ito et al (31) \\
\hline
\end{tabular}

M: male, F: female, up: upper, abd: abdominal, low: lower, lt: left.

disappearance of jaundice during the post operative period. The clinical course of the present case satisfied the first two of the criteria but did not entirely satisfy the others. In this present case, choledochoileostomy was performed because the organization around the pancreas was too prominent to drain the cyst. However, it is conceivable that the obstructive jaundice was caused by the direct compression of the common bile duct by the pancreatic pseudocyst based on the following two reasons. Firstly, the direct serum bilirubin concentration showed a parallel increase with the enlargement of the pancreatic pseudocyst. Secondly, percutaneous transhepatic cholangiography revealed a long smooth-tapered obstruction of the common bile duct which is usually observed in cases with extramural compression by a pseudocyst.

In the present case, intracystic hemorrhage also occurred, followed by its rupture into the intraperitoneal cavity. Although the intracystic hemorrhage with resulting rupture is the most important cause of death in patients with pancreatic pseudocysts (11), the incidence of spontaneous hemorrhage into a pancreatic pseudocyst appears to be a rare phenomenon and is observed only in several percent of all the pancreatic pseudocysts (12-18). Furthermore, rupture of the pancreatic pseudocyst caused by an intracystic hemorrhage is also reported to be an extremely rare phenomenon $(14,19,20)$. Indeed, in Japan, there have been only 11 cases over the past 15 years to the best of our knowledge (Table 2) (21-31).
In summary, we reported a case with pancreatic pseudocysts with two rare complications; obstructive jaundice caused by a pseudocyst compression and intracystic hemorrhage with resultant rupture of the pseudocyst. Thus, the present case emphasizes the importance of careful observation and intensive treatment for the patients with pancreatic pseudocysts because life threatening complications may occur.

\section{References}

1) Kane MG, Krejs GJ. Pancreatic pseudocyst. Adv Intern Med 29: 271, 1984.

2) Gadacz TR, Lillemoe K, Zinner M, Merrill W. Common bile duct complications of pancreatitis evaluation and treatment. Surgery 93: 235, 1983.

3) Mehta AI, McDowell DE. Pancreatic pseudocyst as a cause of jaundice. South Med J 71: 1502, 1978.

4) Skellenger ME, Patterson D, Foley NT, Jordan PH Jr. Cholestasis due to compression of the common bile duct by pancreatic pseudocysts. Am J Surg 145: 343, 1983.

5) Warshaw AL, Rattner DW. Fact and fallacies of common bile duct obstruction by pancreatic pseudocysts. Ann Surg 192: 33, 1980.

6) Otomo Y, Takagi A, Sakiyama T, Nagai G. A case of pancreatic cyst complicated by obstructive jaundice. Geka Shinryo 25: 877, 1983 (in Japanese).

7) Sukigara M, Neya K, Taguchi Y, Koyama I, Yamazaki T, Omoto R. Relief of biliary obstruction after the drainage for the pancreatic pseudocyst. Suizo 3: 50, 1988 (in Japanese, abstract in English).

8) Okuyama $\mathrm{H}$, Ikeda $\mathrm{M}$, Morozumi A, et al. Obstructive jaundice due to 


\section{FuJITA et al}

compression of the common bile duct by a pancreatic pseudocyst. Endoscopic Forum for Digestive Disease 5: 274, 1989 (in Japanese, abstract in English).

9) Noda T, Ueno N, Tamada K, et al. A case of chronic pancreatitis with pseudocysts complicated by infection and obstructive jaundice. Am J Gastroenterol 89: 2066, 1994.

10) Sidel VW, Wilson RE, Shipp JC. Pseudocyst formation in chronic pancreatitis: A cause of obstructive jaundice. Arch Surg 77: 933, 1958.

11) McMahon MJ, Playforth MJ, Hill GL. The management of hemorrhagic complications of pseudocyst and abscesses of the pancreas. Aust N Z J Surg 50: 141, 1980.

12) Sankaran $S$, Walt AJ. The natural and unnatural history of pancreatic pseudocysts. Br J Surg 62: 37, 1975.

13) van Heerden JA, ReMine WH. Pseudocysts of the pancreas. Review of 71 cases. Arch Surg 110: 500, 1975.

14) Bradley EL, Clements JL Jr, Gonzalez AC. The natural history of pancreatic pseudocysts: a unified concept of management. Am J Surg 137: 135, 1979.

15) Sandy JT, Taylor RH, Christensen RM, Scudamore C, Leckie P. Pancreatic pseudocyst. Changing concepts in management. Am J Surg 141: 574, 1981.

16) Beebe DS, Bubrick MP, Onstad GR, Hitchcock CR. Management of pancreatic pseudocysts. Surg Gynecol Obstet 159: 562, 1984.

17) O'Malley VP, Cannon JP, Postier RG. Pancreatic pseudocysts: cause, therapy, and results. Am J Surg 150: 680, 1985.

18) Bresler L, Boissel P, Grosdidier J. Major hemorrhage from pseudocysts and pseudoaneurysms caused by chronic pancreatitis: surgical therapy. World J Surg 15: 649, 1991.

19) Grace RR, Jordan PH Jr. Unresolved problems of pancreatic pseudocysts. Ann Surg 184: 16, 1976.

20) Hanna WA. Rupture of pancreatic cysts: report of a case and review of the literature. Br J Surg 47: 495, 1960.

21) Ishizaki $H$, Watabiki $M$, Nakano $T$, et al. A case report of pancreatic pseudocyst complicated with intraperitoneal rupture. Nippon Shokakibyo Gakkai Zasshi (Jpn J Gastroenterol) 80: 2303, 1983 (Abstract in Japanese).
22) Harigane $M$, Matsumoto $S$, Yamada $Y$, et al. An autopsy case of intraperitoneal hemorrhage caused by pancreatic pseudocyst. Naika 53: 956, 1984 (in Japanese).

23) Yamamoto $M$, Kido $K$, Ishimatsu $S$, et al. A case report of the ruptured pancreatic pseudocyst in the peritoneal cavity. Kyukyuigaku 10: 1159, 1986 (in Japanese).

24) Miyake N, Kurose M, Hayashi D, Nonaka Y, Tanaka I, Tokuda N. A case of pseudo-pancreascyst with simultaneous digestive tract and intraperitoneal hemorrhage. Tsuyama Chuo Byoin Igaku Zasshi 1: 83, 1987 (in Japanese, abstract in English).

25) Kobayashi K, Shiramatsu K, Yoshida M, et al. Review and a case report of pancreatic pseudocyst complicated with intraperitoneal hemorrhage and hemorrhagic shock. Hokkaido Geka Zasshi 33: 271, 1988 (in Japanese, abstract in English).

26) Matsui $I$, Watabiki $M$, Aiba $H$, et al. A case report of pancreatic pseudocyst ruptured into the peritoneal cavity. Nippon Shokakibyo Gakkai Zasshi (Jpn J Gastroenterol) 86: 1225, 1989 (Abstract in Japanese).

27) Hayashi H, Adachi Y, Morinaga K, Higuchi N, Kawasaki K. A pancreatic pseudocyst associated with intraperitoneal hemorrhage. Nippon Shokakibyo Gakkai Zasshi (Jpn J Gastroenterol) 86: 2334, 1989 (Abstract in Japanese).

28) Sekibe T, Tanaka T, Fuse M, et al. A case report of pancreatic pseudocyst ruptured into the peritoneal cavity and the colon. Kanagawa Igaku Gakkai Zasshi 18: 350, 1991 (Abstract in Japanese).

29) Fujii T, Taya N, Matsumoto A, et al. A case report of pancreatic pseudocysts complicated with intraperitoneal hemorrhage. Gastroenterol Endosc 34: 1364, 1992 (in Japanese, abstract in English).

30) Ishitodani T, Nakazawa H, Nichizawa H, Tanaka M, Kudo H. An autopsy case of pancreatic pseudocyst associated with intracystic hemorrhage and ruptured into the peritoneal cavity and the gastrointestinal tract. Nippon Byori Gakkai Zasshi (Tr Soc Pathol Jpn) 82: 224, 1993 (in Japanese).

31) Ito $Y$, Tanegashima A, Nishi K, Sukegawa $Y$, Kimura H. Necrotizing arteritis causing fatal massive intraperitoneal hemorrhage from a pancreatic pseudocyst. Int J Leg Med 106: 324, 1994. 